\title{
A Snapshot of Entrepreneurship Education at Canadian Engineering Schools - A Representative Overview from EETI SIG Members
}

\author{
Tate N. Cao ${ }^{1}$, Kush Bubbar ${ }^{2}$, Wayne H. Chang ${ }^{3}$, Darren Meister ${ }^{4}$, Claude Laguë $^{5}$, Andrew Fisher ${ }^{6}$, Tony Bailetti ${ }^{7}$, Marc Hurwitz ${ }^{3}$, \\ Florian Villaume ${ }^{6}$ \\ ${ }^{1}$ University of Saskatchewan, ${ }^{2}$ University of New Brunswick, ${ }^{3}$ University of Waterloo, ${ }^{4}$ University of Western Ontario, ${ }^{5}$ University of \\ Ottawa, ${ }^{6}$ Memorial University of Newfoundland, ${ }^{7}$ Carleton University \\ tate.cao@usask.ca
}

\begin{abstract}
With the rise of an innovation-based, technology-centric economy over the past two decades, there has been a shift in the market, enabling technological entrepreneurs to build business ventures that have realized accelerated growth and reached considerable scale. This "new economy" has created a need for individuals with a balanced skill set accompanying both business acumen, and technological innovation of complex systems. In response to this need, post-secondary engineering education institutions are teaching more business and entrepreneurship content.

In Canada, most of the major post-secondary engineering education institutions offer some form of entrepreneurial education. However, approaches and programs offered by respective institutions vary in their approach to teaching engineering entrepreneurship, yielding a variety of different program implementations. There is, thus, a strong need to develop a Community of Practice focusing on engineering entrepreneurship education in Canada to foster a more rigorous and collaborative effort to evolve entrepreneurial teaching and learning.

This paper is a first attempt to document and interpret the current state of a select number of Canadian Engineering Entrepreneurship Education programs. The founding members of the Canadian Engineering Education Association's (CEEA) Engineering Entrepreneurship and Technology Innovation (EETI) Special Interest Group (SIG) have collaboratively collected information regarding the current practice of Engineering Entrepreneurship education within their affiliated institutions. This paper examines the Institutional Context, Strategy, Business Infrastructure, as well as the programs employed for Teaching and Learning at both the Undergraduate and Graduate levels. Our goal is to present a snapshot of the current practice for which entrepreneurship education is delivered at the institutions for which the founding members of the EETI SIG reside, as well as, discuss how entrepreneurship intersects with the other areas of engineering education, for example, design, the maker space movement, and professionalism, as well as, many of the Canadian Engineering Accreditation Board's twelve graduate attributes.
\end{abstract}

Résumé - L'émergence d'une nouvelle économie basée sur l'innovation et la technologie au cours des vingt dernières années a permis aux entrepreneurs technologiques de créer des entreprises qui se sont rapidement développées, certaines réussissant même à atteindre une taille importante en peu de temps. La réussite de telles entreprises repose sur des individus possédant des connaissances et des habiletés aux niveaux des affaires ainsi que de l'innovation. En réponse à ces besoins et afin de mieux préparer leurs étudiants à cette nouvelle réalité, les facultés et écoles d'ingénierie offrent de plus en plus de formation en entrepreneuriat et en gestion.

C'est notamment le cas dans la majorité des facultés et écoles d'ingénierie canadiennes. Il s'avère cependant que les programmes offerts ainsi que les approches utilisées pour la formation en entrepreneuriat en ingénierie varient grandement d'une institution à l'autre. D'où la nécessité de développer au Canada une communauté de pratique au niveau de la formation en entrepreneuriat en ingénierie dans le but de favoriser le développement et l'amélioration continue de la formation dans ce domaine à l'échelle nationale.

Cette communication vise à dresser le portrait actuel de la formation en entrepreneuriat en ingénierie pour quelques facultés et écoles d'ingénierie canadiennes. Ensemble, les auteurs, tous membres fondateurs du Groupe d'intérêt en entrepreneuriat en ingénierie et en innovation technologique de l'Association canadienne pour l'éducation en génie (ACEG), ont colligé et partagé les informations relatives aux 'écosystèmes entrepreneuriaux' en place dans leurs institutions respectives. Les thèmes du contexte institutionnel, de la stratégie, des ressources et de l'infrastructure de même que les approches et programmes pédagogiques utilisés aux trois cycles sont abordés. Notre objectif est de présenter un portrait des pratiques qui sont actuellement en place dans chacune de nos institutions. Nous examinons également les nombreux liens et interactions qui existent entre la formation en entrepreneuriat et d'autres facettes de l'éducation en génie : la conception, le mouvement 'maker', le professionnalisme ainsi que plusieurs des qualités requises des diplômés, telles que 
définies par le Bureau canadien d'agrément des programmes de génie.

Keywords: Engineering Entrepreneurship and Technology Innovation, Program Evaluation, Teaching Practice, Special Interest Group, Community of Practice

\section{INTRODUCTION}

In the current business climate, entrepreneurship is a conduit to realize innovation, competitiveness and growth for the Canadian economy. Over the last few decades, many Canadian post-secondary institutions have incorporated entrepreneurship education into their curriculum outside of / or in partnership with their respective business faculty - particularly within engineering. The incorporation of business training into a standard engineering education has contributed to the economic growth and developments in many provinces and regions. Entrepreneurship education can be viewed as an investment on the part of universities to generate and curate economic impact to local ecosystems and train businesscentric engineers to meet the needs of future market demands. Engineering educators have reasons to support engineering entrepreneurship education. First, entrepreneurship is a key contributor to the economic and social growth of communities worldwide [1,2]. According to McKinsey \& Company (2011), "the 21" century will be the century of the entrepreneur" [3]. Therefore, there is a need for educational programs and learning opportunities to support a necessary and widespread entrepreneurial culture.

Additionally, based on findings from a comprehensive survey of more than 500 engineering and technology companies performed between 1995 and 2005 [2], the vast majority of company founders were university graduates holding degrees in STEM disciplines. Successful entrepreneurial ventures rely on creativity and innovation, where innovation must be considered as the successful integration of invention and of commercialization [4] or in terms of new or better ways of doing things that are valued by either individuals or by organizations [5]. To realize the creativity and innovation basis of entrepreneurism often requires founders with both business accumyn and core pragmatic technical skills - the latter for which engineers excel. Engineering professionals are, thus, uniquely positioned to engage in innovation ventures due to their educational background that includes exposure to business, communications, humanities, and social sciences in addition to a strong foundation in natural science, engineering science, and engineering design $[6,7]$.

Furthermore, Engineers Canada has identified 'entrepreneurship, innovation, and creativity' as an essential set of values for the engineering profession in Canada [8]. For entrepreneurship education and associated activities to succeed, requires developing engineering graduates with the ability to utilize their "knowledge for engineering", ability to investigate and analyze problems, and to design a solution for such problems using engineering tools, as well as to design a system that can function in both business and technical domains. They also need to be able to form and build an effective team, manage their project, communicate effectively to team members, customers, as well as other stakeholders in a professional manner. Further, engineering entrepreneurs will need to make decisions ethically based on economic analyses while considering the potential impact on society and the environment as a whole. In this regard, entrepreneurship education is, by definition, an experiential learning opportunity for students and graduates to practice and demonstrate their twelve (12) attributes defined by the Canadian Engineering Accreditation Board (CEAB). This clearly points to the necessity to deliver quality entrepreneurship education not only within undergraduate and graduate programs of studies, but in engineering and also at the professional development / continuing education levels as well. Byers et al. (2003) argued that "it is the responsibility of engineering educators to teach their students to be more innovative and entrepreneurial." [9]

Traditionally, engineering entrepreneurship education has been delivered by either faculty instructors or through engineering entrepreneurship practitioners. Practitioners base their pedagogy on their real-life experiences yielding an uncanny comprehension of the craft and art of entrepreneurship, but often lack the academic rigour to communicate their understanding. On the flip side faculty instructors possess strong academic rigour but often lack practitioner experience to leverage an understanding of entrepreneurship education. There is, thus, a strong need to study entrepreneurship education practice objectively through empirical study via the scholarship of teaching and learning (SoTL). In developing a comprehensive understanding of entrepreneurship education through applying a SoTL methodology, the goal is to improve our effectiveness in delivering entrepreneurial learning outcomes while converging on a set of effective teaching practices across our community of practice. This includes identifying the most appropriate course content, pedagogical methods, and other educational activities for the development and implementation of effective engineering entrepreneurship education. This gap in knowledge also calls for a systematic approach to understand the current practice in engineering entrepreneurship education in order to foster better collaboration in the Canadian Engineering Entrepreneurship Education community.

Literature outside of Canada has provided some frameworks regarding the outcomes of engineering entrepreneurship education. According to Wadhwa et al. 2008, in a study tallying data from 500 new engineering and technology ventures started between 1995 and 2005, 
the average founders age was 39 years old when they started their new ventures with twice as many founders who were 50 or older as those who were 25 or younger. This observation suggests students do not start a business immediately upon graduation [2]. Pistrui et al. (2011) suggested that educational institutions need to provide an educational experience that develops the entrepreneurial minds inside and outside the classroom and result in the education of Entrepreneurially Minded Engineers (EMEs) [10]. Menzies (2009) suggested that entrepreneurship education is a process to increase awareness about entrepreneurship as a potential or future career choice and to develop skills for the readiness of entrepreneurship [11, 12]. Notably, the Kern Engineering Entrepreneurship Network (KEEN) developed three Cs' framework (Curiosity, Connections, Creating Value) [13]. The framework focuses on the inspiration and development of entrepreneurial mindset in engineering students instead of venture creation. This is consistent with the experience in entrepreneurship education at the University of Ottawa Engineering, for which only a small fraction of the students become entrepreneurs immediately or shortly after graduation. We find that the main short-term outcome of our 'entrepreneurial ecosystem' is to better equip students for becoming effective 'agents of change' - i.e. individuals who can promote new ideas, different paradigms, and other types of disruptions within existing organizations; the 'intrapreneurs'.

Another challenge for engineering entrepreneurship education is a lack of empirical research on long term education outcomes as entrepreneurship education is in its infancy. For example, as a pioneer in entrepreneurship education within Canada, the Dr. J. Herbert Smith Centre for Technology Management and Entrepreneurship at the University of New Brunswick has been practicing engineering entrepreneurship education for the past thirtytwo years. Over this tenure, this program has driven regional economic development by creating businesses and local employment. It is unclear, however, whether a similar commitment at various higher-education institutions across Canada will yield similar widespread results. A detailed campaign to capture data to explore the temporal influence of engineering entrepreneurship education at highereducation institutions across Canada can yield such answers but will call for research collaboration among the Canadian Engineering Entrepreneurship educators to better understand and measure the effectiveness of achieving educational outcomes.

The lack of understanding on the effect of pedagogical approaches to teaching entrepreneurship and the desired short- and long-term outcomes also poses another challenge in engineering education - selecting the appropriate course delivery approach. For example, Hulsey et al. (2006) suggest that educators need to integrate entrepreneurship within regular academic programs and curricula while providing co-curricular and other activities and initiatives that support and develop the entrepreneurial interests of students [1]. We observe that the majority entrepreneurial education is delivered through lectures and case studies in a degree program. Additionally, Wilson et al. (2014) suggested a 'pracademic' approach for which practical and academic components are integrated into entrepreneurship education [14]. There is clearly a need to better understand the relationship between curriculum based academic programs and non-academic credited practical programs.

The focus of this overview of entrepreneurship education in Canadian engineering schools was fueled: a) by the need to understand the current practice, $b$ ) to provide recommendations for future development in pedagogy (or andragogy), and c) to forge collaborations between entrepreneurial educators across Canada. Prior to this work, it is the belief of the EETI SIG, that there is an absence of consolidated data presenting the strategic focus, scope, approaches, practices, and challenges and opportunities of how various higher education institutions in Canada deliver their engineering entrepreneurship education.

The main objective of this article is to initiate efforts to begin to fill this knowledge gap. The objectives are summarized below:

- To provide information on the current state of teaching practice in selected Canadian engineering universities

- To give good examples of engineering entrepreneurship education as inspiration and help establish road maps for the other institutions

- To curate interest and forge discussions about how SIG members may collaborate to create a shared knowledge base and common language about entrepreneurship education.

We understand that the journey to become an effective leader in entrepreneurial education does not occur overnight, and it can take a number of different pathways as the study will show. The goal for this study is to spark discussions around the practices in Canadian engineering entrepreneurship education and to create opportunities for establishing collaborations to support the unique needs of the various economic environments for each institution. .

\section{METHODOLOGY}

In order to meet the objectives defined in Section 1, this work proposes a collaborative effort from the founding members of the newly established Engineering Entrepreneurship and Technological Innovation (EETI) Special Interest Group (SIG) through CEEA. In this work, the founding members present an overview of implementations of engineering entrepreneurship education at their respective Canadian engineering institutions. 
The study applies a broad definition of entrepreneurship and entrepreneurship education throughout the overview. This overview assumes that engineering entrepreneurship education impacts students through fostering an entrepreneurial mindset to develop relevant entrepreneurial/business skills, as well as encourage entrepreneurial actions. The outcomes have the potential for positive impact on students' mindset, whilst supporting regional economic growth, job creation, and wealth generation. It is also hypothesized that an entrepreneurial mindset and application of the accompanying skills will benefit society in ways that are beyond the scope of traditional business metrics.

This study employed a framework that was originally developed by the European Commission for their 2008 study_[15]. Their framework structures the different aspects of entrepreneurship education under four domains - the institute or program's 1) strategy, 2) infrastructures, 3) practice in teaching and learning, as well as its 4) outreach activities. The framework is employed in order to facilitate better understanding of the strategy and vision at a university level, the teaching and learning practice at the college and program level, as well as the alignment between institutional vision and program level execution, see Figure 1.

Strategy - how the institutions as a whole, if applicable, support the entrepreneurship education in engineering. We want to understand the current state of institutional: 1) vision, and 2) action plan in Canadian post-secondary institutions, as well as 3) the integration between the College of Engineering and their Business schools.

Institutional Infrastructure - what infrastructures are available to support engineering entrepreneurship education. We want to understand the current state of entrepreneurial education and the supporting resources. We examined the following six domains: 1) the average number of entrepreneurial faculty in any given engineering entrepreneurship education program, 2) the presence of an entrepreneurship center, 3) the related student competition, 4) the availability of student funding, 5) the presence of an incubator/accelerator, as well as 6) the effort of research on entrepreneurship education.

Teaching and Learning - the entrepreneurial learning opportunities offered by the institutions. We explore the following four sub-domains: 1) entrepreneurial courses, 2) entrepreneurial degree programs, 3) common teaching methods, and 4) common course content.

Outreach - how the engineering entrepreneurship program engages in the wider community. We examined the institutions'

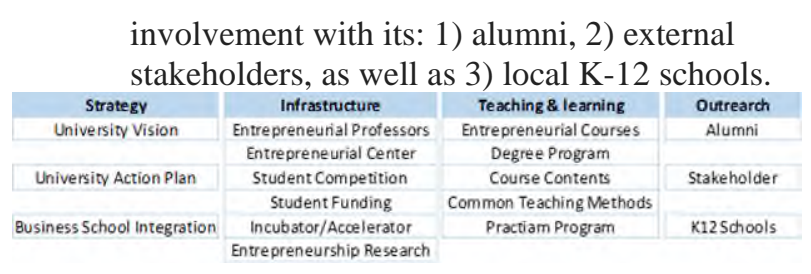

Figure 1 Four domains of the entrepreneurship education framework [15]

The study approached seven universities that were part of the founding team of the CEEA EETI SIG. While we recognize the limited scope of the study, the sampled institutions represent a wide range of engineering entrepreneurship programs. The study geographically covers institutions ranging from Atlantic, Central and Western Canada. It also illustrated the difference between U15 intuitions and the universities with a more distinguished focus on the practice of teaching and learning. The overview examines the qualitative information provided by the instructors for the selected institutions. The limitation of this study and the chosen methodology will be discussed later in the paper along with future work.

\section{FINDINGS}

Based on the comprehensive overview results from the selected seven institutions, we concluded the following findings from the results.

\section{$\underline{\text { Strategy }}$}

In this domain, the study examined three sub-domains: 1) the university wide vision and acknowledgement, 2) the university wide action plan for entrepreneurship, and 3) the integration with the business college within the university.

The study showed that despite the importance of engineering entrepreneurship education, it is not common for universities to have a university wide vision and action plan. Engineering education programs may receive a stronger support in terms of infrastructure and teaching and learning practice from their universities if the university wide plan was in place. It is an area that the SIG members will discuss in the future.

The other notable finding is that about half of the universities surveyed have integrated their engineering entrepreneurship education with their respective business schools, while the other half host their engineering entrepreneurship education within the college of engineering or an entrepreneurship center. Both approaches may present unique advantages, the SIG will explore more deeply into the different practices of each structural choice in the future.

\section{Infrastructure}

In this domain, the study examined: 1) the average number of entrepreneurial faculty in any given engineering entrepreneurship education program, 2) the presence of an entrepreneurship center, 3) the related student competition, 4) the availability of student funding, 5) the presence of an incubator/accelerator, as well as 6) the presence of research 
activity on entrepreneurship education. We seek to build an understanding of the common resources required to conduct engineering entrepreneurship education and provide opportunities for our colleagues to communicate and share practices that worked well in their institutions.

The results showed that most of the institutions have on average between 2 to 10 full time equivalent faculty teaching engineering entrepreneurship programming with most programs operating within an entrepreneurship centre. A majority of the programs organize and offer some form of in-house student competition, while most of the institutions use common space and student competitions to generate interest in entrepreneurship. More importantly, this observation illustrates that these institutions have adopted a 'pracademic' approach to entrepreneurship education that combines extracurricular activities with formal instruction.

We also found that over half of the institutions identified funding support for students who pursue entrepreneurship as part of their education. Half of the institutions offer their own incubator facilities. These results demonstrate that universities can act as a broker for entrepreneurial students in pursuit of venture creation outside the traditional education role. Notably, some universities are also equipped with a Scalerator ${ }^{\mathrm{TM}}$ program to accelerate revenue generation through an increase in sales for successful startups in their local ecosystem, thus creating a conduit to rapidly grow into established businesses. The variety of approaches the various universities are utilizing to act as early cultivators of commercialization, and their effect for facilitating venture creation and community formation is another interesting direction for the SIG to explore in the future.

We also found that research on entrepreneurial education was rare in the engineering entrepreneurship programs surveyed, which is consistent with literature. This result shows that research on engineering entrepreneurship education is still in its infancy in Canada, especially when compared to its counterpart south of the border.

\section{Teaching and Learning}

In this domain, the study focuses on the aspects that directly relate to the students' learning and experience of entrepreneurship. This domain consists of four subdomains: 1) entrepreneurial courses, 2) entrepreneurial degree programs, 3) common teaching methods, and 4) common course content.

This domain showed the greatest variety in how the institutions deliver their entrepreneurship education programs, which is also consistent with literature. Due to the practice focused nature of entrepreneurship education, there are two established approaches for offering the knowledge and training to students - the academic and the non-academic stream. In the academic stream, most of the institutions offer between 4 to 10 entrepreneurial courses. Similarly, most of the institutions that use the academic training programs employ an Undergraduate certificate, diploma or dual degree options, or Master programs. In comparison, no institution in our survey is currently offering a Ph.D program in entrepreneurship. Notably, many institutions in the United States offer Ph.D programs in Technology Innovation and Entrepreneurship including MIT and Stanford. This suggests another area for future growth for the Canadian Engineering Entrepreneurship education program surveyed in this work.

It should be noted that the non-academic stream of entrepreneurial training programs is offered by some institutions in our survey. About half of the institution have an established entrepreneurial Co-op program set in place as a training vehicle. We seek to investigate this more deeply in relation to teaching approaches - academic versus non-academic programming - to explore an optimal balance between the two approaches to support the unique needs of each institution.

In terms of common teaching methods, lectures are still the most employed delivery method and are used in all seven universities. Case studies, project teams and entrepreneurs-in-residence are also widely used in the surveyed institutions. Business mentors, (sector specific) technical engineers-in-residence, and designers-inresidence are not as widely employed. It might be a structure worthy of exploration for the institutions with appropriate resources.

In terms of course content, the surveyed institutions vary significantly. The common course contents include entrepreneurial design, design-thinking, lean, multidisciplinary design capstone, venture creation, as well as communication skills. Strategy, intellectual property, sales and human resources are offered in less programs. These results are also consistent with literature. SIG members will work together to seek more clarity to define essential entrepreneurial skills for their engineering students.

\section{Outreach}

In this domain, the study attempts to understand the institutions' involvement with its: 1) alumni, 2) external stakeholders, as well as 3) local K-12 schools. The result demonstrates good involvement with entrepreneurial alumni and local entrepreneurs. However, the involvement with local companies and investors are not universal. It may be an area that many universities can consider as a supplementary to their current programs. Similarly, the involvement with local K-12 schools is rare, it may also be a potential area of growth for many institutions if resources permit.

\section{DISCUSSION}

Our survey of the current practices on engineering entrepreneurship education within the institutions of our current EETI SIG members resulted in two key findings. First, in agreement with previous literature, we found a 
wide range of course contents, delivery methods, program designs, and integration with non-academic practice. However, unlike the literature with origins in the United States, our overview identified the current state and practices in engineering entrepreneurship education. We also identified that the common goals in the surveyed institutions is to develop entrepreneurial and innovation mindsets in our engineering students.

The second finding is the desire and need for empirical research to support program structure as well as pedagogy practice. The institutions in the SIG employed a diverse range of teaching and training methods, as well as delivery programs. Many programs are effectively adopted based on the situation and resources available at each institution. However, it is a common desire to learn from the practices in other institutions. This further supports the need for an evidence-based common knowledge of engineering entrepreneurship education. By working collectively, EETI SIG members can develop and validate an effective framework and common practices to support the training of Canadian engineering "entrepreneurs" and "intrapreneurs".

Lastly, this overview also identified significant future opportunities in Canadian Engineering Entrepreneurship Education. There is a need for a more comprehensive study on engineering entrepreneurship education practice across the nation. For example, we want to understand the current state and practice in French Canada. Finally, the current collaborative relationships between university and private sector (incubators, accelerators, and venture funds) should be studied, as well as, the collaborations established between different academic institutions.

\section{CONCLUSION}

Canadian higher education institutions are actively involved in developing and offering entrepreneurship education to their engineering students. This overview demonstrates the variety of each institution's approach using a cohesive framework which consists of four subdimensions. The overview identified a number of strong initiatives and noteworthy practices that are present in the current EETI SIG member institutions. It also identified the need for a common knowledge and evidence-based theoretical framework for conducting the education programs in Canada.

The EETI SIG has been established to act as a Community of Practice to facilitate the creation of an inventory of different engineering schools' courses and programs centred around entrepreneurship and business education, to foster the collaboration in conducting engineering entrepreneurial research, and to promote the status of engineering entrepreneurship education across Canada.

\section{Acknowledgements}

We wish to thank the Canadian Engineering Education Association's Board of Directors for supporting the formation of the Engineering Entrepreneurship and Technology Innovation Special Interest Group, along with all the EETI SIG members who contributed to this work.

\section{References}

[1] L. L. R. a. B. K. Hulsey, "Seeding Entrepreneurship Across Campus: Early Implementation Experiences of the Kauffman Campuses Initiative.," Final report to the Ewing Marion Kauffman Foundation, 2006.

[2] V. R. F. a. B. R. Wadhwa, "Education and Tech Entrepreneurship.," Ewing Marion Kauffman Foundation, Kansas City, MO, USA., 2008.

[3] McKinsey \& Company., "The Power of Many - Realizing the socioeconomic potential of entrepreneurs in the $21 \mathrm{st}$ century.," McKinsey \& Company., 2011.

[4] T. Brzustowski, "Innovation = Invention + Commercialization: A Systems Perspective.," Optimum Online - The Journal of Public Sector Management, vol. 36(3), no. (available at www.optimum online.ca)., 2006.

[5] Council of Canadian Academies., "Innovation and Business Strategy: Why Canada Falls Short.," Council of Canadian Academies, Ottawa, ON, Canada., 2009.

[6] C. A. o. Engineering, "Wealth through Technological Entrepreneurship; Challenges and Opportunities for Canadians.," Canadian Academy of Engineering, Ottawa, ON, Canada (available at http://www.cae-acg.ca/wp content/uploads/2014/01/ Eng\%20 Is, 1998.

[7] N. A. o. Engineering, " The Engineer of 2020: Visions of Engineering for the New Century.," National Academies Press, Washington, DC, USA., 2004.

[8] Engineers Canada, "A Vision for the Engineering Profession," Engineers Canada, Ottawa, ON, Canada., 2009.

[9] T. T. S. S. S. a. P. W. Byers, "Entrepreneurship: Its Role in Engineering Education," The Bridge, vol. 43, no. 2, pp. 35-40, 2013.

[10] D. R. K. D. C. a. P. S. Pistrui, "Assessing the Entrepreneurial Mindset in Undergraduate Engineering Education: New Methods and Emerging Practices in the Kern Entrepreneurship Education Network.," in NCIIA 15th Annual Open Conference, Washington, 2011.

[11] C. a. M. W. Parsley, "The Teaching and Practice of Entrepreneurship within Canadian Higher Education Institutions.," Industry Canada, Ottawa, ON, Canada., 2010.

[12] T. Menzies, "Entrepreneurship and the Canadian Universities: Report of a National Study on Entrepreneurship Education.," Faculty of Business, Brock University, St. Catharines, ON, Canada., 2009.

[13] J. \&. G. J. Santiago, "Developing an Entrepreneurial Mindset Using the KEEN Framework for a Digital Communication System Course.," in ASEE Annual Conference and Exposition., 2018.

[14] M. E. H. M. C. M. G. a. S. G. Wilson, "Engineering Education: Engineering a Pracademic Approach.," in 
Paper ASEE-NWMSC2104-3C2 presented at the The 2014

ASEE North Midwest Section Conference. American

Society for Engineering Education, Washington, DC,

USA., 2014.

[15] K. E. Wilson, "Entrepreneurship education in Europe.

Entrepreneurship and higher education.," 2008. 